\title{
Obstacles to Using Assistive Technology for Older Adults - Results from a Focus Group Analysis
}

\author{
Marina FOTTELER ${ }^{\mathrm{a}, 1}$, Beate RISCH ${ }^{\mathrm{b}}$, Petra GAUGISCH ${ }^{\mathrm{b}}$, Jan-Lukas FURMANEK $^{\mathrm{a}}$, \\ Walter SWOBODA ${ }^{\mathrm{a}}$, Sarah MAYER ${ }^{\mathrm{c}}$, Brigitte KOHNc ${ }^{\mathrm{c}}$, Dhayana DALLMEIER ${ }^{\mathrm{c}}$ and \\ Michael DENKINGER ${ }^{\mathrm{c}}$ \\ ${ }^{a}$ DigiHealth Institute, Neu-Ulm University of Applied Sciences, Neu-Ulm, Germany \\ ${ }^{\mathrm{b}}$ Fraunhofer-Institute for Industrial Engineering IAO, Stuttgart, Germany \\ ${ }^{\mathrm{c}}$ Geriatric Research Unit, Agaplesion Bethesda Clinic, Ulm, Germany
}

\begin{abstract}
Much hope is placed in the use of assistive technologies (AT) to support older adults and retain their independence and quality of life. AT could also be a way to help fulfill the increasing requirements of caring for an aging population. While many devices are freely available, successful and broad adoption is progressing slowly. In a qualitative analysis, we investigated the popularity of AT and the willingness to and obstacles for use. Eleven older adults aged 62-85 participated in three groups, each focusing on a specific age-related case example. Using content analysis, statements have been categorized into three levels: the affected person, their surroundings, and supportive devices. Information (knowledge, consultation) was the topic spoken about the most $(\mathrm{n}=101)$, followed by statements focusing on everyday life and the use of assistive devices $(n=99)$. Comments on economic topics carried the least weight $(n=28)$. The biggest obstacles for the reluctant adoption of AT don't seem to be acceptance issues but rather a lack of knowledge of AT and where to get counseling. Thus, the provision and promotion of coherent information material and accessible consultation for users and relatives should be prioritized. AT training for healthcare professionals can provide further opportunities.
\end{abstract}

Keywords. assistive technology, older people, focus group, obstacles

\section{Introduction}

Much hope is placed in the use of assistive technologies (AT) to support older people with daily activities and retain their independence and quality of life [1]. Considering the increasing requirements to care for an aging population and the lack of qualified staff, AT could also be part of the solution to the demographic challenges faced by many western health care systems [2].

Similarly to the target group of older people, AT are characterized by a high level of heterogeneity. The term covers, among others, in-house emergency alarms, sensor systems, e.g., for fall detection, digital medication reminders, or household robots [3, 4]. Many AT are freely available and older adults are generally willing to use AT [5]. However, broad adoption in Germany is still lacking, as emphasized in a recently

\footnotetext{
${ }^{1}$ Marina Fotteler, DigiHealth Institute, Neu-Ulm University of Applied Sciences, Wileystrasse 1, 89231 Neu-Ulm, Germany; E-mail: marina.fotteler@hnu.de.
} 
published report on "older people and digitalization" by the German federal government [4]. From a scientific perspective, the effectiveness of AT for older, and especially frail older people remains unclear despite a growing body of literature $[1,6,7]$.

A workshop with potential AT users in southern Germany was conducted to (1) gain insight into the level of knowledge of AT and (2) investigate obstacles people face when wishing to use AT. Particularly for the German context, our study can provide additional insight into the reasons for the hesitant adoption of AT.

\section{Methods}

We conducted focus group discussions, a qualitative approach that allows participants to interact, exchange ideas, and build upon each other's arguments [8]. A group of experts with backgrounds in geriatric medicine, nursing, therapy, public health, and information technology developed case examples, so-called personas to be used as the basis for the discussions and eliminating the need to speak of own deficits or problems. Table 1 presents the most important characteristics of the personas. Each group was guided by a moderator making sure participants spoke about (1) wishes and worries of the persona, (2) possibilities of supporting them, and (3) requirements for successful use of assistive devices. Ideas were documented together on a large-size paper template placed in the center.

Table 1. The three personas for the focus group discussions

\begin{tabular}{|c|c|c|c|}
\hline Persona & Age & Living situation & Health condition \\
\hline Ms. Owl & 82 & $\begin{array}{l}\text { Single, no relatives, lives in an assisted } \\
\text { living residence }\end{array}$ & $\begin{array}{l}\text { Nocturnal unrest, back pain, risk of } \\
\text { falling }\end{array}$ \\
\hline Mr. Swallow & 69 & $\begin{array}{l}\text { Retired, married, wife is still working } \\
\text { (part-time) }\end{array}$ & $\begin{array}{l}\text { Incontinence, food and liquid intake } \\
\text { too low, fear of stigmatization }\end{array}$ \\
\hline Ms. Sparrow & 62 & $\begin{array}{l}\text { Lives with her husband (retired) in a } \\
\text { suburban house, in early retirement }\end{array}$ & $\begin{array}{l}\text { Loneliness, visually and hearing } \\
\text { impaired, forgetfulness, resigned }\end{array}$ \\
\hline
\end{tabular}

Participants were recruited in the in- and outpatient departments of a large geriatric clinic to also include frail people at risk of losing autonomy. Participation was voluntary, and all participants were informed orally and in writing about the project and signed a consent form. Participants were free to leave at any time. After an introduction and presentation of the personas, participants distributed independently into the groups. The project team only made sure that partners were in separate groups. Discussions were recorded.

The audio records were transcribed and checked by a second person. Using structured content analysis, a set of categories was developed, tested, and finalized in three cycles [9]. Two people independently categorized the data. Cited statements were translated into English by the first author and checked by all other authors.

\section{Results}

Eleven people aged 62-85 (mean $=72.7)$ participated in the 45-minute group discussions. Table 2 lists participants and their groups. Most participants were female $(n=7)$ and, with the exception of one person $(\mathrm{H})$, all still lived in their own home. A total of 503 individual comments were made. Person D only spoke four times, while person I made 75 contributions. 
Table 2. Overview of the study participants

\begin{tabular}{ccccc}
\hline Person & Sex & Age & Group & Comments \\
\hline A & female & 62 & Ms. Owl & 31 \\
B & female & 70 & Ms. Owl & 41 \\
C & female & 70 & Ms. Owl & 56 \\
D & female & 65 & Ms. Sparrow & 4 \\
E & female & 67 & Ms. Sparrow & 54 \\
F & female & 67 & Ms. Sparrow & 15 \\
G & male & 80 & Ms. Sparrow & 73 \\
H & male & 83 & Ms. Sparrow & 59 \\
I & female & 85 & Mr. Swallow & 75 \\
J & male & 74 & Mr. Swallow & 47 \\
K & male & 77 & Mr. Swallow & 48 \\
\hline
\end{tabular}

Relevant comments were categorized into three levels, relating (1) directly to the affected person, (2) to their surroundings (i.e., their partner, society), and (3) to assistive devices. The five themes information, everyday life, acceptance, cultural/social aspects, and economic aspects were identified within these levels. Figure 1 summarizes the number of codes within this matrix, Table 3 lists the topics talked about.

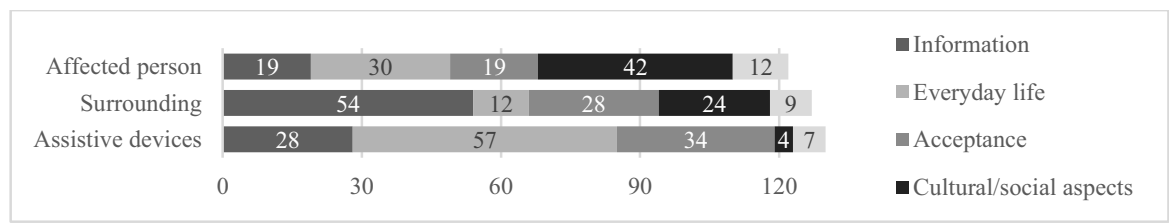

Figure 1. Frequency of codes within the three levels and across the five themes

Most comments related to information $(n=101)$, particularly the wish for an exchange with like-minded people and the need for more and clearer counseling on existing AT, their acquisition and use, e.g., from relatives.

- "This [topic incontinence] is always pushed away. We have senior citizens' meeting every two weeks, nothing like this is spoken about there, and that would be so important, particularly for our age." (group swallow, person I)

- $\quad$ "Today there are also many relatives or children who don't know much about it, who do not know what/how can I help or what does the person need or what is there at all. "(group owl, person A)

- "Yes, and advice is also about all-round advice, also financially." (group sparrow, person F)

- $\quad$ "But then this advice, I just need to look on the Internet to see the number of different retailers and wheelchairs or walkers available, that's unbelievable." (group owl, person C)

Dealing with age-related issues, potential adaptions to the house, and the use, training, and integration of AT were topics in the category everyday life $(n=99)$.

- "We hardly have a place for house alterations where someone can go and get advice." (group owl, person A)

- $\quad$ "I think you have to make sure that someone really comes into the house and simply goes along with the people and leads them to accept the technology." (group sparrow, person E) 
- "This is for my generation, it is, um, it would be important that I can go somewhere and ask how do I have to do it; and above all, that I am told several times. My children, they already say that, but it happens so quickly and then you don't know anymore." (group swallow, person I)

- $\quad$ "If you don't have it [internet/smartphone skills], it doesn't help, then the whole app doesn't help." (group swallow, person J)

- "And you can no longer change the batteries yourself at all [of the hearing aid]." (group sparrow, person G)

Additionally, suggestions for specific assistive devices were collected. Classic resources, like a shower seat, incontinence pads, hearing aids, or walking sticks, were named, but also more innovative devices and AT such as a light sensor, a speech detection system, a smartphone application showing the next public toilet, and a digital library for audiobooks. In total, 446 individual codes were allocated.

Table 3. Topics talked about, ordered within the code matrix

\begin{tabular}{llll}
\hline \multicolumn{1}{c}{ Topic } & \multicolumn{1}{c}{ Affected person } & Surrounding & Assistive devices \\
\hline Information & - Wish for counseling, & - Assist with searching for & - Lack of information on \\
existing AT and their use & information & - Understandable info \\
& - Speaking to relatives and/or & - Help with technology & - Recommendations by \\
& like-minded & selection and use & - Reliable diagnostic \\
Everyday & - Dealing with age-related & - Difficulty to get doctor's & - Usability (physical, \\
life & deficits and symptoms & appointments & cognitive) \\
& - Difficulties using assistive & - Respect deficits/compromise & - Need for training \\
& devices & - Accessibility (readability, & - Integration into daily life \\
& & understandability, etc.) & - Architectural integration \\
Acceptance & - Acceptance of own situation & - Acceptance, understanding & - Acceptance of the \\
& - Be proactive & for affected persons & assistive device \\
Cultural/ & - Isolation, loneliness & - Self-care & - Data protection \\
social & - Rejection of help & - Enable participation and self- & - Loss of personal relations \\
aspects & - Wish to show consideration & determination for affected & - Risk of dehumanization \\
& - Shame/worry what others & - Reach out to affected persons, & \\
Economic & might think & keep in contact & \\
aspects & - Individual financial & - lack of transparency regarding & - Affordability, \\
& situation & insurance coverage & transparency \\
& & & - Information on cost \\
& & & reimbursement options \\
\hline
\end{tabular}

\section{Discussion}

Not knowing where to get information on AT might be one of the biggest obstacles for broader use in Germany [10-12]. Users know some selected solutions but in general seem overwhelmed by the range of products [3, 10]. While some local initiatives for counseling exist, the target group does not seem to be aware of these offers. A central point of access, advertised through different channels and providing advice about acquisition, use, and integration of AT, could be a possible solution. Other research also suggests that the knowledge gap extends not only to older adults and their relatives but also to health care professionals who could provide licensed guidance for older citizens, increase trust in the technology, and help to overcome concerns or fears related to AT $[3,13]$. Contrary to stereotypical beliefs, most older adults are willing to use AT $[5,14$, 
15]. Participants in this study emphasized the need for repeated training, user-friendly, accessible design, and clarity on cost reimbursement or insurance coverage $[1,15]$.

Limitations include convenience sampling, the small number of participants, and the use of different personas. Nevertheless, coupled with existing research, the results can provide guidance for community or policy action promoting AT use. In focus group settings, shy or reserved people might get passed over [8]. Person D only made four statements, while three people from the same group each made more than 50 comments, potentially being too dominant. However, other participants felt they were in a safe and trusted environment. Participant K emphasized this by talking about his experience with incontinence pads and stating that he has not even mentioned this in front of his friends.

There is much hope that AT can contribute to the independence and improvement of quality of life for older adults and ease the pressure on health care delivery. A prerequisite for broad adoption of AT is the provision of accessible and targeted information material, offers for counseling and training for health care professionals. To generate a valid evidence base and adequately inform users, their relatives and others, further scientific evaluation of the effectiveness of AT for older adults is needed.

\section{References}

[1] Fischer, SH, David, D, Crotty, BH, Dierks, M, et al., Acceptance and use of health information technology by community-dwelling elders. International Journal of Medical Informatics, 2014;83(9): 624-635.

[2] Soar, J and Seo, Y, Health and Aged Care Enabled by Information Technology. Annals of the New York Academy of Sciences, 2007;1114(1):154-161.

[3] Paulicke, D, Buhtz, C, Meyer, G, Schwarz, K, et al., Technikweiterbildungen für pflegende Angehörige - Bildungs- und Beratungskonzepte zu assistiven Technologien für pflegende Angehörige von Menschen mit Demenz. PADUA, 2019;14(4):255-264.

[4] Achter Altersbericht der Bundesregierung: Ältere Menschen und Digitalisierung. 2020, Bundesministerium für Familie, Senioren, Frauen und Jugend (BMFSFJ): Berlin. p. 162.

[5] Mitzner, TL, Boron, JB, Fausset, CB, Adams, AE, et al., Older Adults Talk Technology: Technology Usage and Attitudes. Comput Human Behav, 2010;26(6):1710-1721.

[6] Ekeland, AG, Bowes, A, and Flottorp, S, Effectiveness of telemedicine: A systematic review of reviews. International Journal of Medical Informatics, 2010;79(11):736-771.

[7] Holthe, T, Halvorsrud, L, Karterud, D, Hoel, K-A, et al., Usability and acceptability of technology for community-dwelling older adults with mild cognitive impairment and dementia: a systematic literature review. Clinical interventions in aging, 2018; 13:863-886.

[8] Wong, LP, Focus group discussion: a tool for health and medical research. Singapore Med J, 2008; 49(3): 256-60.

[9] Schreier, M, Varianten qualitativer Inhaltsanalyse: Ein Wegweiser im Dickicht der Begrifflichkeiten. Forum: Qualitative Sozialforschung, 2014;15(1):18

[10] Tsertsidis, A, Challenges in the provision of digital technologies to elderly with dementia to support ageing in place: a case study of a Swedish municipality. Disability and Rehabilitation: Assistive Technology, 2020.

[11] Gjestsen, MT, Wiig, S, and Testad, I, What are the key contextual factors when preparing for successful implementation of assistive living technology in primary elderly care? A case study from Norway. BMJ Open, 2017;7:1-9.

[12] de Witte, L, Steel, E, Gupta, S, Ramos, VD, et al., Assistive technology provision: towards an international framework for assuring availability and accessibility of affordable high-quality assistive technology. Disability and Rehabilitation: Assistive Technology, 2018;13(5):467-472.

[13] Newton, L, Dickinson, C, Gibson, G, Brittain, K, et al., Exploring the views of GPs, people with dementia and their carers on assistive technology: a qualitative study. BMJ open, 2016;6:1-7.

[14] Guner H and Acarturk C. The use and acceptance of ICT by senior citizens: a comparison of technology acceptance model for elderly and young adults. Universal Access in the Information Society, 2018.

[15] Claes V, Devriendt E, Tournoy J and Milisen K, Attitudes and perceptions of adults of 60 years and older towards in-home monitoring of the activities of daily living with contactless sensors: An explorative study. International Journal of Nursing Studies, 2015; 52(1):134-148. 